\title{
Strategi Pengembangan Ekowisata Mangrove Tongke-Tongke di Kabupaten Sinjai
}

\author{
Tamrin Salim ${ }^{1},{ }^{*}$, Risma Illa Maulany ${ }^{2}$, Roland A Barkey ${ }^{2}$ \\ 1Program Studi Ilmu Kehutanan, Pascasarjana IImu Kehutanan, Universitas Hasanuddin \\ 2Fakultas Kehutanan Fakultas Kehutanan, Universitas Hasanuddin \\ *E-mail: cha_tham@yahoo.co.id
}

\begin{abstract}
Tourist's perceptions as well as the impacts of tourism activities towards the local people are vital to strategically addressed problems encountered in ecotourism development. The perception of tourists needs to be identified in order to achieve optimum use of tourism facilities. Therefore, this study was aimed to analyse factors contributed in the development of Tongke-tongke Mangrove Ecotourism by portraying the perspective of tourists as the main target of tourism in proposing development strategics of the area as community-based ecotourism. The study was conducted from November 2017 to Januari 2018. The data were collected through questionnaire distribution and interviews to relevant stakeholders. Then, they were analysed qualitatively by using SWOT to formulate strategies in developing Tongke-tongke Mangrove Ecotourism. The results generate in quadrant I which means that the main priority in developing the ecotourism on the site were through the combination of strengths and opportunities of the area. This can be achieved by (a) optimizing the main interests of the ecotourism objects in Tongke-tongke by maintaining its nature potentials; (b) introducing more trainings to the local people in particular in the field of tourism; (c) maintaining and nurturing the ecotourism group who acts as a caretaker of the ecotourism activities in the area; and (d) improving coordination and communication with the local government (Sinjai Regency).
\end{abstract}

Keywords: Community based ecotourism, mangrove ecotourism, SWOT analysis, tourist's perceptions DOI: http://dx.doi.org/10.24259/jhm.v10i2.3997

\section{PENDAHULUAN}

Pemanfaatan kawasan mangrove untuk dikembangkan sebagai kegiatan pariwisata berbasis ekowisata merupakan alternatif pemanfaatan yang rasional diterapkan di kawasan pesisir karena dapat memberi manfaat ekonomi dan jasa lingkungan tanpa mengeksploitasi mangrove. Pemanfaatan jasa lingkungan berupa ekowisata akan mendorong upaya konservasi ekosistem mangrove sebagai daerah penyangga kawasan konservasi (Kusmana dan Istomo, 1993). Pemanfaatan mangrove untuk ekowisata juga sejalan dengan pergeseran minat wisatawan dari old tourism menjadi new tourism yang mengelola dan mencari daerah tujuan ekowisata yang spesifik, alami, dan memiliki keanekaragaman hayati (Rutana, 2011).

Pengelolaan mangrove di Desa Tongke-Tongke awalnya merupakan swadaya masyarakat Kelompok Pelestari Sumber Daya Alam Aku Cinta Indonesia (KPSDA ACl) dan telah berhasil membangun hutan mangrove dengan tujuan untuk perlindungan pantai dan perkampungan penduduk. Sebelumnya kawasan ini merupakan kawasan pesisir pantai yang banyak dikonversi menjadi daerah tambak dan pemukiman oleh masyarakat setempat. Adanya konversi hutan mangrove menjadi lokasi tambak dan pemukiman tersebut disebabkan oleh lonjakan harga udang selama krisis moneter yang mendorong petani tambak untuk memberdayakan hutan mangrove dan kemudian mudahnya akses usaha dengan merelokasi hutan mangrove menjadi habitat ikan atau udang dibandingkan dengan pembukaan lahan baru. Namun hal tersebut tidak bertahan lama seiring dengan penurunan produktivitas di kawasan tersebut yang kemudian memotivasi masyarakat lokal Sinjai di wilayah pesisir untuk merehabilitasi kawasan tersebut melalui penanaman kembali mangrove. Kini keberadaan hutan mangrove tumbuh dan berkembang sesuai dengan yang diharapkan meskipun pernah rusak akibat penebangan, hutan mangrove Tongke-Tongke saat ini dijadikan sebagai kawasan wisata yang berkontribusi secara ekonomi kepada masyarakat sekitarnya.

Pengembangan wisata mengacu pada persepsi wisatawan dan juga dampaknya kepada masyarakat secara ekonomi, serta konsservasi lingkungan sebagai suatu kawasan ekowisata. Persepsi wisatawan perlu diketahui agar dalam pengembangan fasilitas wisata dapat lebih mudah diarahkan sehingga penggunaan fasilitas wisata dapat lebih optimal (Rusneni, 2013). Oleh karena itu, penelitian ini bertujuan untuk mengidentifikasi faktor-faktor pengembangan ekowisata mangrove Tongke-Tongke khususnya ditinjau dari 
persepsi wisatawan yang dalam hal ini juga melibatkan beberapa komponen stakeholders lainnya seperti unsur pemerintah setempat dan masyarakat pengelola serta masyarakat lokal yang melakukan usaha di sekitar lokasi wisata.

Selain itu, penelitian ini akan mengungkap target serta segmen pasar dari obyek wisata yang ada di kawasan mangrove Tongke-tongke agar kemudian upaya pengembangan obyek wisata di daerah tersebut dapat disesuaikan dengan kebutuhan pasar. Sehubungan dengan itu, penelitian ini dilakukan dengan tujuan untuk memperoleh rumusan dan mengusulkan strategi pengembangan mangrove Tongke-Tongke sebagai kawasan ekowisata berbasis masyarakat.

\section{METODE PENELITIAN}

\subsection{Waktu dan Tempat}

Penelitian ini akan dilaksanakan selama 2 bulan, dimulai dari akhir bulan November 2017 sampai akhir bulan Januari 2018 di Kawasan Wisata Mangrove Tongke-Tongke Kabupaten Sinjai. Jangka waktu keseluruhan dalam penelitian ini digunakan untuk melakukan berbagai kegiatan terkait penelitian yang diantaranya didahului dengan studi literatur dan kemudian melakukan orientasi lapangan, pengambilan data primer melalui pendistribusian kuisioner kepada para wisatawan serta wawancara terstruktur terhadap pemerintah setempat yang dalam hal ini adalah Dinas Pariwisata dan Balai Perkebunan dan Kehutanan Kabupaten Sinjai serta masyarakat pengelola ekowisata Mangrove Tongke-tongke, Kelompok Pencinta Sumberdaya Alam (KPSDA) Aku Cinta Indonesia $(\mathrm{ACl})$ dan masyarakat lokal yang melakukan usaha di sekitar lokasi wisata. Data sekunder juga dikumpulkan untuk memperoleh data berupa angka atau gambar terkait penelitian pada beberapa instansi/lembaga yang terkait seperti Kantor Bappeda Sinjai, Kantor Balai Penyuluhan Perkebunan dan Kehutanan Sinjai, Kantor Kecamatan Sinjai Timur, dan Kantor Desa Tongke-Tongke.

\subsection{Teknik Pengambilan Data}

Pengambilan sampel dalam penelitian ini dilakukan dengan Purposive Sampling dan Accidental Sampling. Pengambilan data dengan Purposive Sampling diterapkan pada stakeholders yang berkepentingan langsung terhadap pengembangan obyek wisata mangrove Tongke-Tongke yakni Dinas Pariwisata dan Dinas Kehutanan Kabupaten Sinjai serta KPSDA ACI dan masyarakat yang melakukan usaha di Desa Tongke-Tongke. Wawancara terstruktur dilakukan pada Dinas Pariwisata Sinjai (Kepala Bidang Pengembangan Pariwisata) dan penyuluh pendamping dari Balai Perkebunan dan Kehutanan Sinjai terkait pengelolaan. Wawancara juga dilakukan pada masyarakat pengelola yaitu KPSDA ACI serta masyarakat lokal yang melakukan usaha di sekitar lokasi wisata bertujuan untuk menggali informasi terkait kondisi serta jumlah aksesibilitas, infrastruktur, dan juga pengelolaan wisata di kawasan wisata mangrove Tongke-Tongke. Sementara pengambilan data dengan Accidental Sampling melalui kuisioner diterapkan pada wisatawan yang berkunjung ke obyek wisata mangrove Tongke-Tongke dengan jumlah sampel sebanyak 75 orang untuk mendapatkan data diri wisatawan (karakteristik demografis dan pola kunjungan) wisatawan, persepsi terhadap Objek dan Daya Tarik Wisata, persepsi terhadap Infrastruktur dan Aksesibilitas, serta persepsi terhadap pengelolaan objek wisata mangrove Tongke-Tongke.

\subsection{Teknik Analisis Data}

Teknik analisis data yang digunakan dalam penelitian ini yaitu analisis deskriptif kualitatif. Analisis deskriptif ini untuk menjawab tujuan penelitian yang pertama dan kedua, yaitu mendeskripsikan persepsi wisatawan terhadap pengembangan ekowisata mangrove Tongke-Tongke dan faktor-faktor pengembangan ekowisata mangrove Tongke-Tongke. Hasil analisis deskriptif kemudian dianalisis lebih dalam dengan pendekatan SWOT (Strength, Weakness, Opportunity, and Threat) yang digunakan untuk menyusun rencana pengembangan ekowisata mangrove Tongke-Tongke.

\section{HASIL DAN PEMBAHASAN}

\subsection{Persepsi Wisatawan}

Dari hasil penelitian terhadap karakteristik wisatawan dan juga pola kunjungan wisatawan maka dapat diketahui kunjungan wisatawan pada obyek wisata mangrove Tongke-Tongke rata-rata adalah pelajar atau 
mahasiswa yakni sebesar $56 \%$ (Gambar 1). Hal ini menunjukan bahwa obyek wisata mangrove Tongke-Tongke sangat diminati oleh kaum muda. Informasi yang diperoleh oleh wisatawan tentang obyek wisata sebanyak $67 \%$ responden mengatakan dari teman. Hal ini juga menunjukan bahwa promosi wisata mangrove Tongke-Tongke belum dilakukan secara maksimal baik dari media cetak maupun elektronik. Menurut Salam dkk (2000), keberhasilan pengembangan wisata di kawasan wisata mangrove Sundarbans, Bangladesh, didukung oleh penyediaan informasi dan juga promosi menarik tentang potensi daya tarik alam serta fitur lainnya yang berada di kawasan hutan mangrove melalui website.

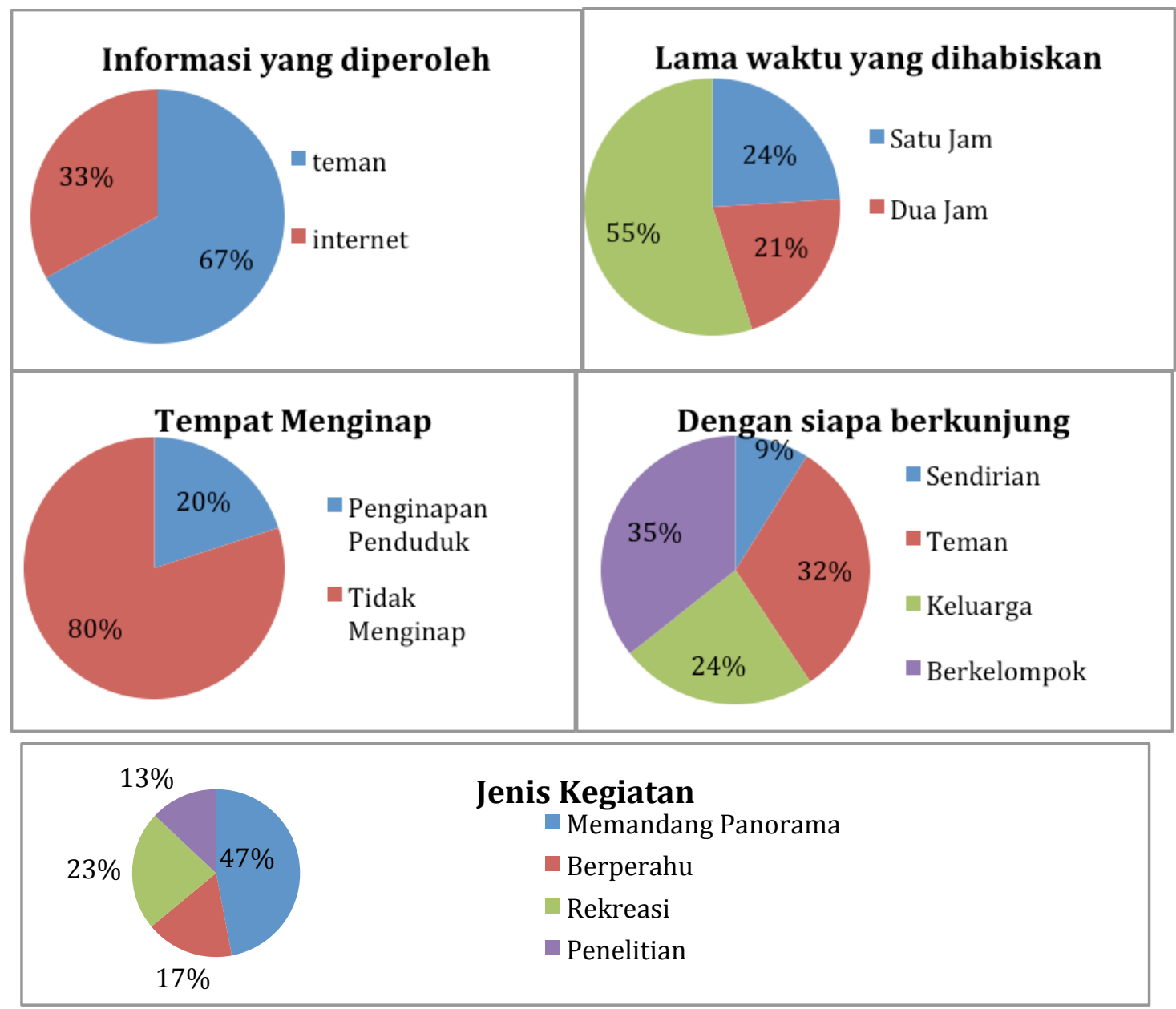

Gambar 1. Karakteristik Demografis wisatawan yang berkunjung ke Kawasan Tongke-Tongke, Kabupaten Sinjai

Selama berkunjung kegiatan yang dilakukan oleh wisatawan pun sangat terbatas. Hal ini terlihat dari $47 \%$ responden yang mengatakan kegiatan yang bisa dilakukan hanya memandang panorama mangrove dengan berjalan sepanjang jembatan tracking (Gambar 2). Hal tersebut juga tidak lepas dari masih belum memadainya sarana prasarana wisata penunjang seperti menara pengamatan satwa. Oleh karena itu, penambahan kegiatan berwisata dan obyek wisata yang dapat dilihat menjadi peluang pengembangan wisata di kawasan ini. Saparinto (2007), menyatakan bahwa kawasan mangrove sebagai obyek pengembangan ekowisata dikatakan optimal apabila lokasi dan jenis kegiatan telah dapat ditentukan, keteraturan dan keserasian sarana dan prasarana disesuaikan dengan kondisi obyek, kenyamanan dan keamanan wisatawan terjamin. 


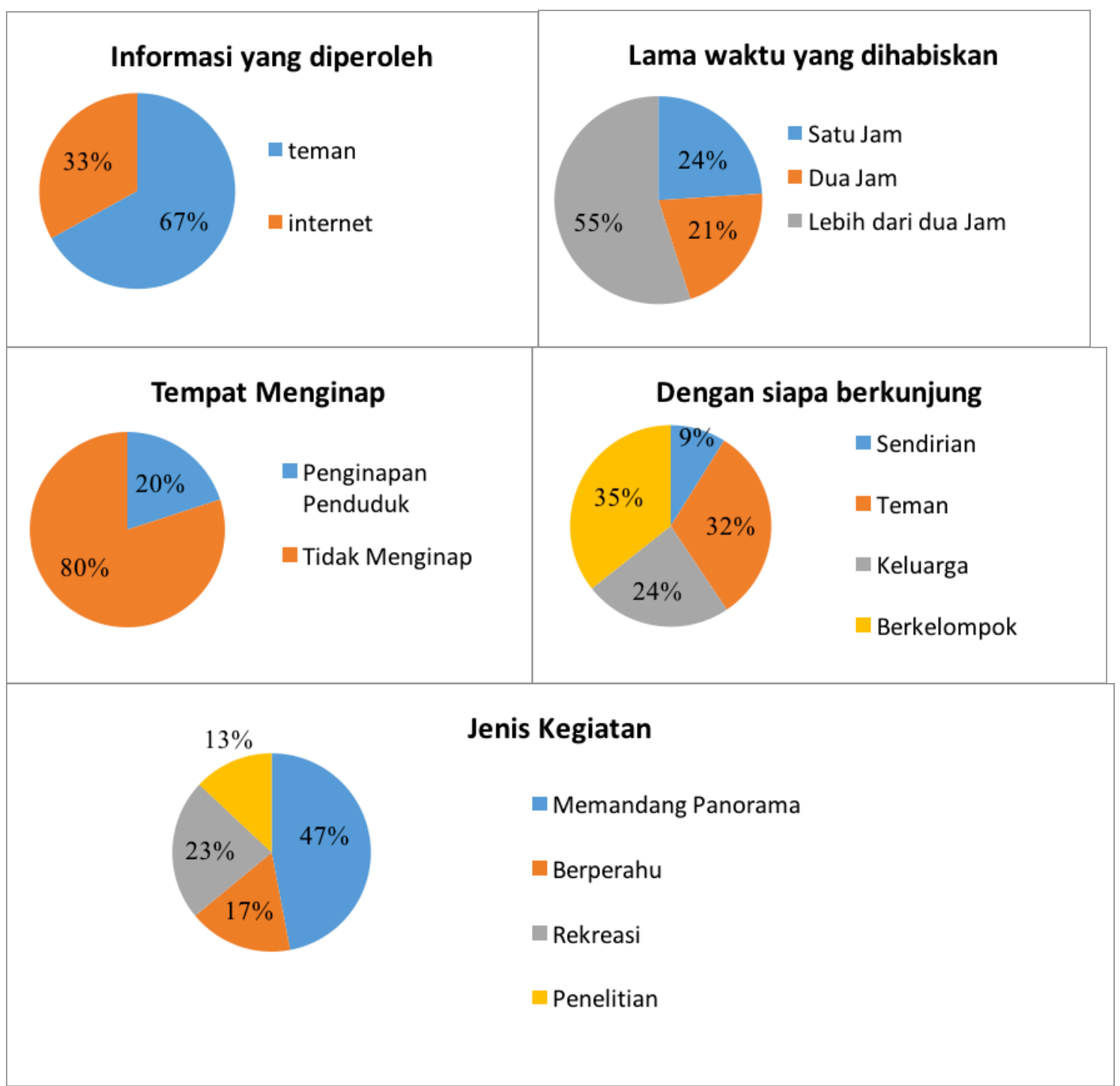

\section{Gambar 2. Deskripsi Pola Kunjungan Wisatawan ke Kawasan Wisata Tongke-Tongke} Kabupaten Sinjai

Dari aspek aksesibilitas jalan menuju kawasan wisata mangrove Tongke-Tongke sudah cukup baik meskipun pada beberapa titik jalan Desa Tongke-Tongke masih berlubang dan belum diaspal. Hal tersebut jelas terlihat dari $44 \%$ responden yang memberikan saran agar kondisi jalan tersebut diperbaiki. Sedangkan untuk sarana prasarana wisata masih belum memadai (Gambar 3). Hal ini terlihat dari belum adanya infrastruktur wisata seperti menara pengamatan, papan interpretasi yang kurang, pondok untuk penerimaan wisatawan, dan penataan para pedagang yang berjualan pada lokasi tersebut juga belum tertata secara baik. Yoeti (2001), mengungkapkan bahwa tingkat kemudahan mencapai ke daerah wisata tersebut dari daerah atau tempat tinggal wisatawan akan mempengaruhi perkembangan daerah wisata tersebut. Lebih jauh Yoeti (2001), juga menyatakan bahwa ketersediaan sarana prasarana yang cukup seperti homestay, warung makan, toilet, tempat parkir, dan sebagainya mempengaruhi kunjungan wisatawan. Wisatawan lebih sering tertarik oleh fasilitas yang akrab dengan arsitektur lokal daripada akomodasi modern yang sering ditemui di daerah asalnya. 

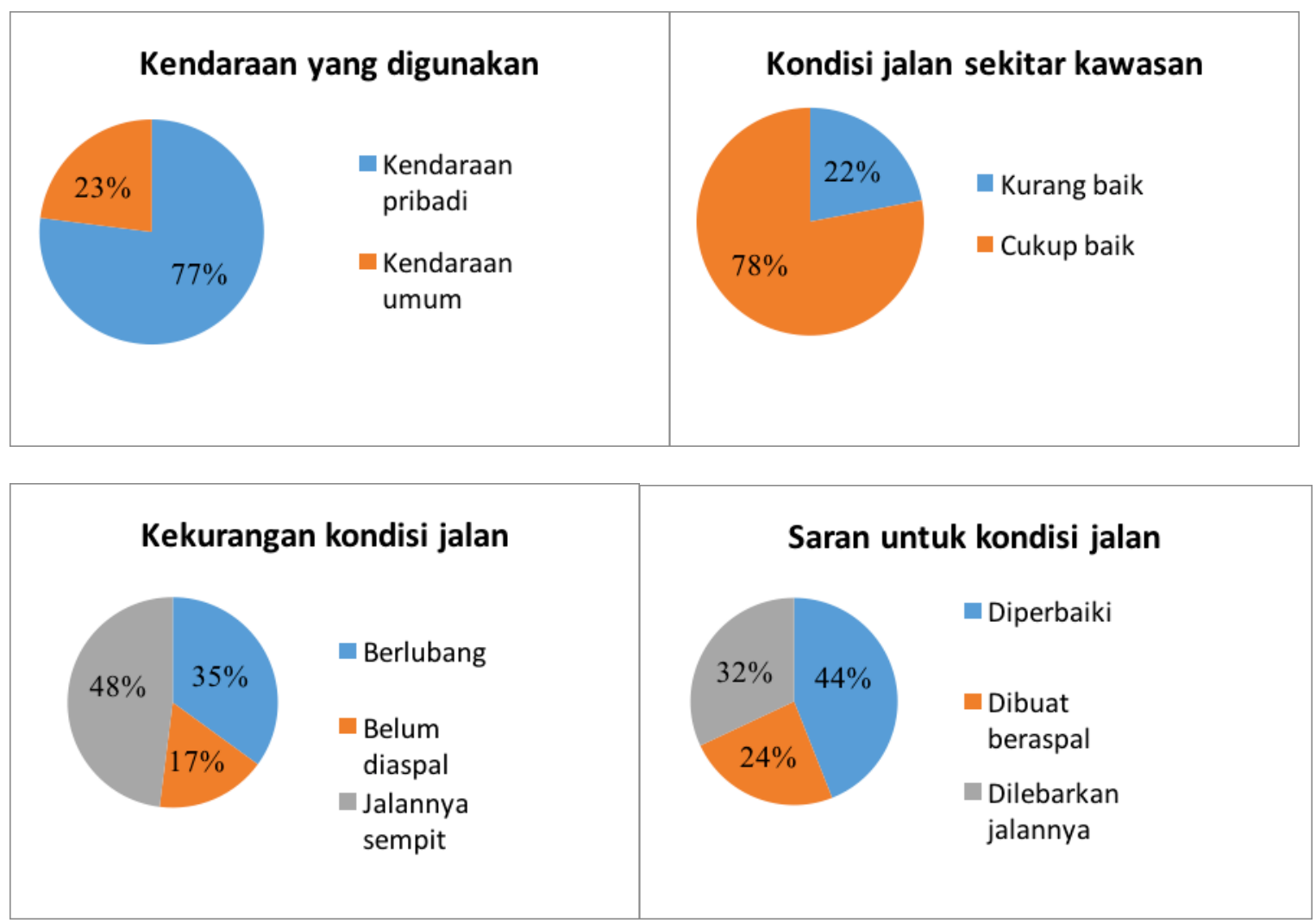

Gambar 3. Aksesibilitas di Kawasan Wisata Mangrove Tongke-Tongke

Dari aspek obyek dan daya tarik wisata, wisatawan yang berkunjung dapat menikmati panorama hutan mangrove Tongke-Tongke dengan berjalan sepanjang jalur tracking. Selain itu keberadaan satwa burung, kelelawar, dan juga satwa air dapat dinikmati oleh wisatawan selama berkunjung. Mutaqqin (2012), menyatakan obyek dan daya tarik wisata di Cagar Alam Pulau Sempu meliputi pantai, mangrove, hutan hujan tropis rendah, ekosistem danau dan gua. Hutan mangrove merupakan kawasan yang paling sering dikunjungi wisatawan karena paling mudah dijangkau. Sementara itu Hadinoto (1996), menyatakan bahwa obyek dan daya tarik wisata (ODTW) dapat merupakan alam, budaya, tata hidup dan sebagainya yang memiliki daya tarik untuk dikunjungi atau menjadi sasaran bagi wisatawan.

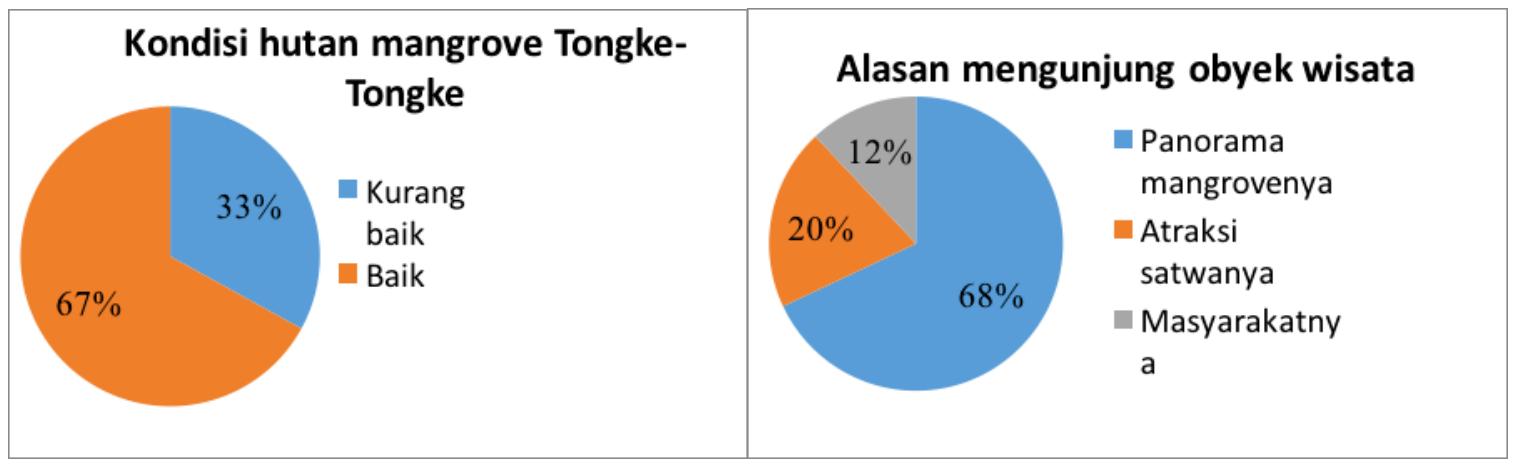




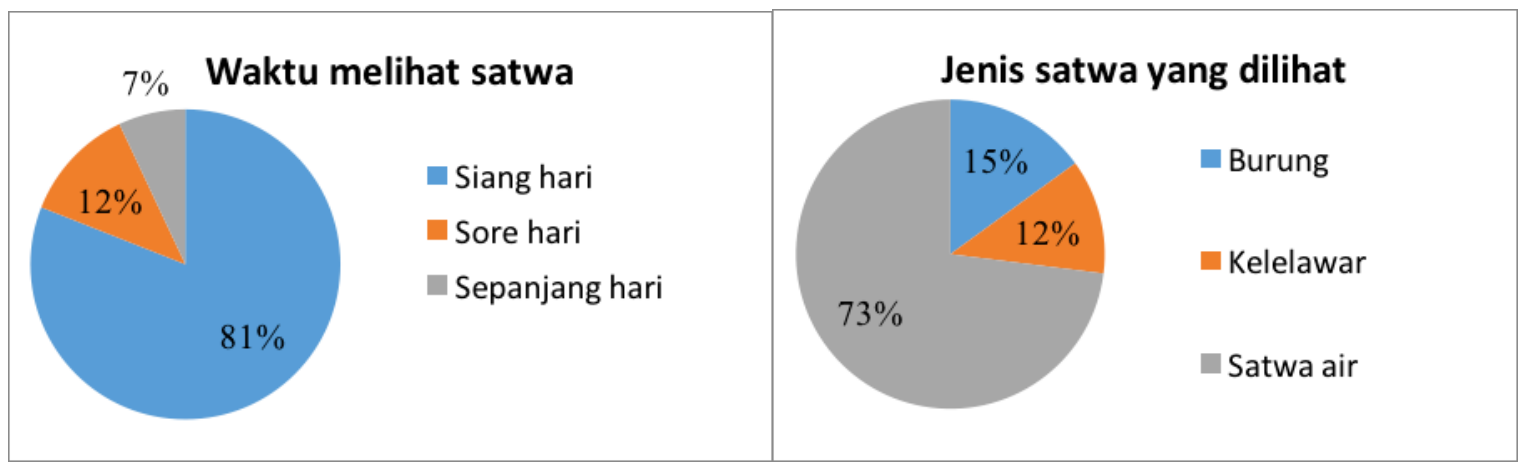

Gambar 4. Obyek dan Daya Tarik Wisata pada WisataMangrove Tongke-Tongke Kabupaten Sinjai.

Dari aspek pengelolaan yang meliputi keamanan, kebersihan, promosi, dan juga pelayanan wisata menurut wisatawan belum dilakukan secara maksimal. Sebanyak $68 \%$ responden mengatakan keamanan yang ada pada kawasan wisata mangrove Tongke-Tongke terbilang baik. Hal ini dikarenakan selama berkunjung wisatawan merasakan keramahan masyarakat setempat, tidak terganggu dengan wisatawan lainnya, dan tidak ada gangguan dari satwa yang dapat membahayakan jiwa wisatawan. Untuk kebersihan pada kawasan wisata sebanyak $60 \%$ respondenmengatakan baik. Hal ini terlihat dengan tersedianya tempat sampah pada lokasi wisata. Meskipun terbilang baik, namun pada beberapa titik tertentu disekitar obyek wisata masih banyak terlihat sampah yang berserakan. Demartoto (2008), menyatakan bahwa kebersihan dan keamanan pada kawasan wisata sangat mempengaruhi kunjungan wisatawan ke obyek wisata tersebut. Wisatawan lebih suka memilih berkunjung ke obyek wisata yang alami dan bersih. Selain itu faktor keamanan selama berkunjung pun menjadi pertimbangan utama sebelum melakukan perjalanan wisata.

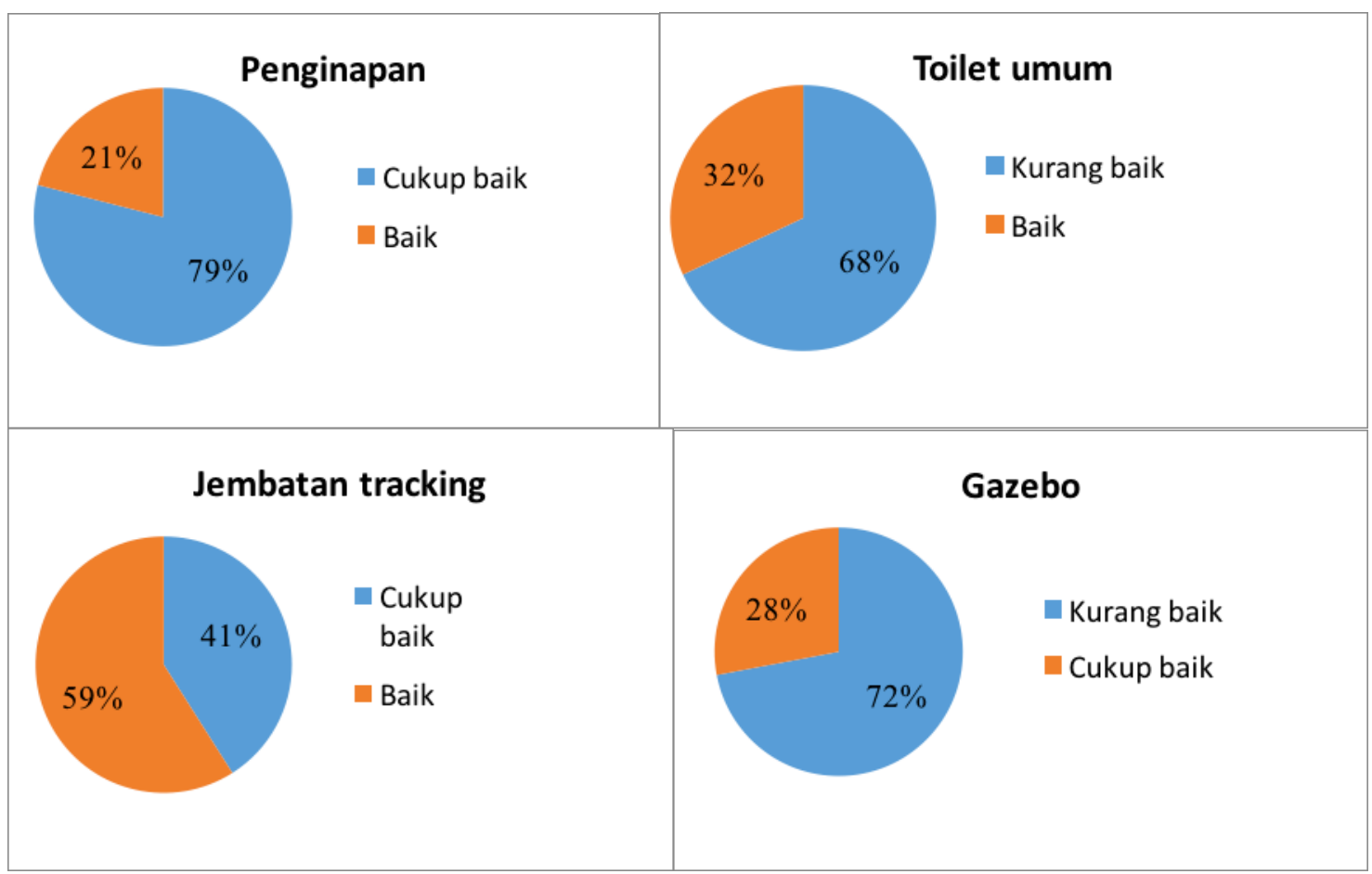

Gambar 5. Sarana dan Prasarana di Kawasan WisataMangrove Tongke-Tongke Kabupaten Sinjai.

Untuk promosi dan juga pelayanan menurut wisatawan belum dilakukan secara maksimal. Promosi wisata sendiri menurut $76 \%$ responden menyatakan kurang baik. Hal ini dapat dilihat dari belum maksimalnya promosi melalui media seperti leaflet, surat kabar, poster, televisi, dan website. Meningkatkan pengelolaan melalui promosi wisata dapat dilakukan melalui kerja sama dengan berbagai instansi terkait seperti Departemen 


\section{品}

Kebudayaan dan Pariwisata dengan meningkatkan kuantitas dan kualitas materi promosi dalam bentuk leaflet, brosur, booklet, CD interaktif dan website (Demartoto, 2008). Sedangkan pelayanan sendiri sebanyak $69 \%$ mengatakan kurang baik. Hal tersebut juga dikarenakan selama berkunjung wisatawan belum didampingi oleh pemandu wisata dan kurangnya papan interpretasi yang menjelaskan potensi ekologi dan potensi lainnya yang dimiliki Desa Tongke-Tongke. Wisatawan yang berkunjung untuk penelitian atau studi banding.

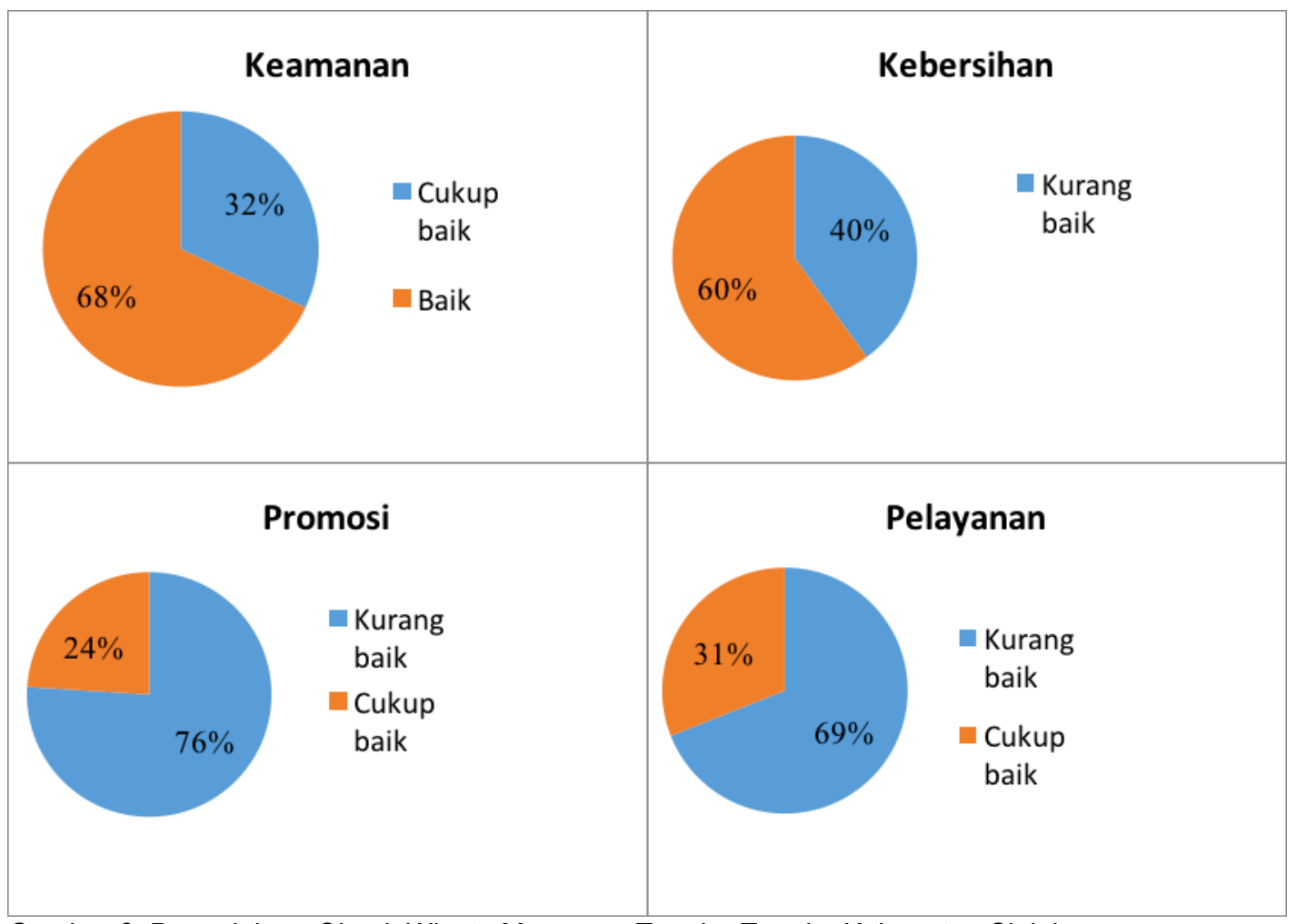

Gambar 6. Pengelolaan Obyek Wisata Mangrove Tongke-Tongke Kabupaten Sinjai.

\subsection{Keterlibatan Masyarakat dan Pemerintah}

\subsubsection{Keterlibatan Masyarakat}

Berdasarkan hasil penelitian responden yang berasal dari Pemerintah setempat (Dinas Pariwisata dan Balai Perkebunan dan Kehutanan Kabupaten Sinjai), masyarakat pengelola dan masyarakat yang melakukan usaha di sekitar kawasan wisata menyatakan bahwa masyarakat belum dilibatkan dalam pembangunan sarana prasarana wisata (jembatan tracking, pondok informasi, gazebo), dari aspek pengelolaan responden menyatakan masyarakat belum dilibatkan dalam proses perencanaan. Sedangkan keterlibatan masyarakat saat ini menurut responden masih sebatas pada mengikuti kegiatan penyuluhan dan usaha wisata yang dilakukan seperti menyediakan toilet berbayar, jasa homestay, kios dan warung makan, menjual kuliner, dan parkiran kendaraan. Keterlibatan masyarakat dalam pengembangan ekowisata dilakukan dengan menyewakan homestay, menyewakan perahu bermotor, berjualan, dan sebagai pemandu telah berlangsung lama hal ini menjadikan profesi sebagai penyedia jasa wisata sebagai profesi utama yang berdampak pada peningkatan pendapatan masyarakat sekitar (Muttaqin dkk, 2012). Menurut Subadra (2006), ekowisata memberikan peluang dan akses kepada masyarakat lokal untuk mengembangkan usaha pendukung pariwisata seperti; toko kerajinan, toko cindramata (souvenir), warung makan dan lain-lain. Tingkat keterlibatan masyarakat dalam ekowisata sangat berbeda dan ini tergantung dari jenis potensi, pengalaman, pengetahuan dan keahlian yang dimiliki oleh individu atau masyarakat lokal tersebut.

Hasil penelitian juga menunjukan kendala yang dihadapi oleh pihak pengelola adalah kurangnya sumberdaya manusia di bidang pariwisata.Meskipun membuka lapangan pekerjaan dan manfaat ekonomi bagi masyarakat sekitar namun belum adanya tenaga profesional dalam bidang pariwisata dan kurangnya keterlibatan masyarakat dalam perencanaan pengembangan dapat menjadi ancaman bagi pengembangan ekowisata mangrove Tongke-Tongke. Muttaqin dkk (2012), menyatakan partisipasi masyarakat yang masih 
cenderung bersifat pelaksana dan belum pada tataran perencanaan dan evaluasi, rendahnya kemampuan SDM lokal dalam bidang pariwisata menjadi kelemahan serta ancaman dalam pengembangan ekowisata di Cagar Alam Pulau Sempu.

\subsubsection{Keterlibatan Pemerintah}

Kepala Bidang Pengembangan Dinas Pariwisata Sinjai mengemukakan bahwa keterlibatan pemerintah daerah Sinjai khususnya Dinas Pariwisata dalam mendukung kegiatan pariwisata yaitu dengan penetapan Peraturan Daerah (Perda) Nomor 6 Tahun 2017 tentang retribusi karcis. Selain penetapan Perda Nomor 6 Tahun 2017, dari aspek sarana prasarana wisata pemerintah daerah telah membangun jembatan tracking, pondok informasi, dan menyedikan tempat sampah, membangun gerbang wisata, dan membuat papan penunjuk arah bagi wisatawan. Upaya yang dilakukan oleh pemerintah daerah dalam pengembangan ekowisata mangrove juga dapat dilakuan dengan penanaman bibit mangrove, melengkapi sarana dan prasarana, area parkir, dan melakukan kerjasama yang antara pemerintah, masyarakat maupun swasta (Novianti, 2016).

Dari aspek pengelolaan dan peningkataan kapasitas masyarakat pemerintah daerah melakukan pendampingan kepada Kelompok Sadar Wisata ACl sebagai pihak pengelola, melakukan penyuluhan kepada masyarakat, dan mendampingi wisatawan yang melakukan penelitian. Menurut Pramesuary dkk (2015), dukungan pemerintah dalam pengembangan ekowisata diwujudkan dengan kegiatan berupa program pengembangan sarana prasarana wisata, program peningkatan ekonomi melalui pinjaman modal kepada masyarakat, peningkatan kualitas lingkungan dengan melakukan sosialisasi dan pelatihan tentang pelestarian lingkungan hidup, membentuk kelembagaan sebagai pengelola dan pelatihan pemandu wisata. Meskipun ada dukungan dari Pemerintah Kabupaten Sinjai, namun keterbatasan anggaran dalam pengelolaan dan masih kurangnya sosialisasi yang dilakukan dapat menjadi ancaman dalam pengembangan mangrove Tongke-Tongke sebagai kawasan ekowisata.

Tabel 1. Hasil rangkuman wawancara dengan Pemerintah Kabupaten Sinjai

\begin{tabular}{|c|c|c|}
\hline No. & Aspek Keterlibatan & Kegiatan yang dilakukan Pemerintah \\
\hline 1. & Legalitas & $\begin{array}{l}\text { membuat dan menerapkan Perda Nomor } 6 \text { Tahun } 2017 \text { tentang } \\
\text { Retribusi tempat wisata }\end{array}$ \\
\hline 2. & $\begin{array}{l}\text { Sarana dan prasarana } \\
\text { wisata }\end{array}$ & \multirow{2}{*}{$\begin{array}{l}\text { membangun jembatan tracking, gazebo, pondok informasi, } \\
\text { dan } \\
\text { menyediakan tempat sampah } \\
\text { menggalang dukungan Bank Sulselbar membangun gerbang } \\
\text { wisata dan papan penunjuk arah } \\
\text { melakukan pendampingan kepada Kelompok Sadar Wisata ACI } \\
\text { selaku pengelola obyek } \\
\text { mengikutkan Desa Tongke-Tongke sebagai Desa Wisata }\end{array}$} \\
\hline 3. & Pengelolaan & \\
\hline 4. & $\begin{array}{l}\text { Peningkatan } \\
\text { Masyarakat }\end{array}$ & $\begin{array}{l}\text { Melakukan penyuluhan kepada Kelompok Tani Hutan KPSDA } \\
\text { ACI Desa Tongke-Tongke. } \\
\text { Melakukan pendampingan kepada wisatawan yang datang } \\
\text { untuk penelitian }\end{array}$ \\
\hline
\end{tabular}

\subsection{Faktor-Faktor Pengembangan}

Berdasarkan hasil penelitian terhadap persepsi wisatawan, keterlibatan masyarakat, dan keterlibatan pemerintah daerah maka dapat diketahui faktor-faktor dalam pengembangan ekowisata mangrove TongkeTongke. Faktor-faktor yang dapat dikembangkan pada obyek wisata mangrove Tongke-Tongke untuk menjadi kawasan ekowisata meliputi aspek sarana prasarana wisata, aspek pengelolaan, keterlibatan masyarakat dalam usaha wisata dan pengelolaan, dan aspek legalitas atau payung hukum.

Selain itu aspek-aspek ekowisata yang tidak terdapat pada wisata biasa juga dapat dikembangkan pada wisata mangrove Tongke Tongke sebagai kawasan ekowisata yang meliputi aspek edukasi, aspek ekonomi, aspek budaya, dan juga aspek konservasi. Aspek edukasi yang dapat dikembangkan berupa kegiatan menanam mangrove, mempelajari jenis mangrove yang ada di Tongke-Tongke, jenis burung, jenis satwa air dan juga jenis kelelawar endemik Sulawesi yang ada pada kawasan wisata tersebut. Dari aspek ekonomi memberikan peluang 
pada masyarakat lokal yang dapat diperoleh melalui jasa penginapan, toilet berbayar, tukang parkir, kios dan kantin yang menjual berbagai makanan kuliner. Dari aspek budaya dapat berupa kuliner atau makanan tradisional yakni ikan asap dan makanan yang diolah dari buah mangrove. Dari aspek konservasi pemerintah melarang masyarakat agar tidak melakukan penebangan hutan mangrove melalui penetapan kawasan hutan mangrove Tongke-Tongke sebagai hutan lindung.

\subsection{Strategi Pengembangan Ekowisata}

Berdasarkan hasil analisis SWOT yang dilakukan dalam rangka pengembangan ekowisata mangrove Tongke-tongke ke dalam matriks dengan terlebih dahulu mengidentifikasi faktor internal dan faktor eksternal yang berpengaruh terhadap pengembangan ekowisata mangrove Tongke-Tongke. Kemudian dilakukan perhitungan bobot faktor internal dan eksternal untuk mengetahui letak kuadran yang strategis dalam pengembangan ekowisata yang dianggap lebih penting untuk dilakukan. Hasil analisis perhitungan bobot faktor internal dan eksternal melalui tabulasi skor IFAS - EFAS, diperlihatkan pada Tabel 2 dan Tabel 3.

Tabel 2. Analisis Faktor Strategi Internal (IFAS)

\begin{tabular}{|c|c|c|c|}
\hline \multirow{2}{*}{ Faktor Internal } & \multicolumn{3}{|c|}{ Nilai } \\
\hline & Bobot & Rating & Skor \\
\hline \multicolumn{4}{|l|}{ Kekuatan } \\
\hline a) Antusias wisatawan yang berkunjung cukup tinggi. & 0,20 & 4 & 0,80 \\
\hline $\begin{array}{l}\text { b) Kealamian panorama hutan mangrove Tongke- } \\
\text { Tongke. }\end{array}$ & 0,20 & 4 & 0,80 \\
\hline c) Aksesibilitas menuju kawasan cukup baik & 0,10 & 3 & 0,30 \\
\hline d) Keamanan dalam kawasan wisata cukup baik & 0,10 & 3 & 0,30 \\
\hline \multicolumn{2}{|l|}{ Jumlah sub bobot } & 14 & 2,20 \\
\hline \multicolumn{4}{|l|}{ Kelemahan } \\
\hline $\begin{array}{l}\text { a) Wisatawan yang berkunjung rata-rata pelajar yang } \\
\text { belum memiliki pekerjaan dan penghasilan. }\end{array}$ & 0,05 & 2 & 0,10 \\
\hline b) Infrastruktur wisata belum memadai. & 0,20 & 4 & 0,60 \\
\hline c) Kurangnya promosi wisata. & 0,05 & 2 & 0,10 \\
\hline d) Kurangnya kegiatan dalam wisata. & 0,05 & 2 & 0,10 \\
\hline e) Kurangnya nilai edukasi & 0,05 & 2 & 0,10 \\
\hline \multicolumn{2}{|l|}{ Jumlah sub bobot } & 12 & 1,00 \\
\hline Jumlah bobot & 1 & 26 & \\
\hline \multicolumn{4}{|c|}{ Nilai skore Kekuatan - Kelemahan (IFAS) $=2,20-1,00=1,20$} \\
\hline
\end{tabular}

Tabel 3. Analisis Faktor Eksternal (EFAS)

\begin{tabular}{|c|c|c|c|}
\hline \multirow{2}{*}{$\begin{array}{ll}\text { Faktor Eksternal } \\
\end{array}$} & \multicolumn{3}{|c|}{ Nilai } \\
\hline & Bobot & Rating & Skor \\
\hline \multicolumn{4}{|l|}{ Peluang } \\
\hline a) Adanya penyuluhan kepada masyarakat. & 0,10 & 3 & 0,30 \\
\hline $\begin{array}{l}\text { b) Adanya Perda No } 6 \text { Tahun } 2017 \text { tentang retribusi } \\
\text { tempat wisata. }\end{array}$ & 0,20 & 4 & 0,80 \\
\hline $\begin{array}{l}\text { c) Telah terbentuknya Kelompok Sadar Wisata } \mathrm{ACl} \\
\text { sebagai pengelola. }\end{array}$ & 0,10 & 3 & 0,30 \\
\hline d) Keterlibatan masyarakat dalam usaha wisata & 0,10 & 2 & 0,20 \\
\hline e) Adanya dukungan dari pemerintah & 0,10 & 2 & 0,20 \\
\hline Jumlah sub bobot & & 14 & 1,80 \\
\hline \multicolumn{4}{|l|}{ Ancaman } \\
\hline a) Kurangnya tenaga profesional dalam bidang & 0,05 & 2 & 0,10 \\
\hline pariwisata. & 0,05 & 3 & 0,15 \\
\hline b) Anggaran yang terbatas dalam pengelolaan. & 0,05 & 1 & 0,05 \\
\hline
\end{tabular}


c) Kurangnya sosialisasi dari pemerintah.

d) Kurangnya keterlibatan masyarakat dalam perencanaan.

\begin{tabular}{cccc} 
& $\begin{array}{c}\text { Jumlah sub bobot } \\
\text { Jumlah bobot }\end{array}$ & 1 & 0,35 \\
\hline & Nilai Skor Peluang - Ancaman (EFAS) & $=1,80-0,35=1,45$ \\
\hline
\end{tabular}

Hasil analisis faktor internal (IFAS) dan faktor eksternal (EFAS), selanjutnya digunakan untuk membuat grafik letak kuadran SWOT guna menentukan letak kuadran strategi yang dianggap memiliki prioritas tinggi dan mendesak untuk segera dilaksanakan. Grafik kuadran analisis SWOT diformulasikan sebagai sumbu X dan $Y$, dimana sumbu $X$ adalah IFA (Kekuatan - Kelemahan) sedangkan sumbu Y adalah EFAS (Peluang - Ancaman). Nilai kedua sumbu ini dinyatakan berdasarkan hasil skoring dari Tabel 2 (IFAS) yakni sebesar 1,20 dan Tabel 3 (EFAS) dengan nilai 1.

\begin{tabular}{|c|c|c|}
\hline Eksternal & $\begin{array}{l}\text { Kekuatan (S) } \\
\text { 1. Antusias wisatawan yang } \\
\text { berkunjung cukup tinggi. } \\
\text { 2. Kealamian panorama hutan } \\
\text { mangrove Tongke-Tongke. } \\
\text { 3. Aksesibilitas menuju kawasan } \\
\text { cukup baik. } \\
\text { 4. Keamanan di dalam kawasan } \\
\text { wisata sangat baik. }\end{array}$ & \begin{tabular}{lll}
\multicolumn{3}{l}{ Kelemahan (W) } \\
1. & Wisatawan yang \\
& berkunjung rata-rata \\
& pelajar yang belum \\
& memiliki pekerjaan dan \\
& penghasilan. \\
2. & Infrastruktur wisata \\
belum memadai. & \\
3. & $\begin{array}{l}\text { Kurangnya promosi } \\
\text { wisata. }\end{array}$ \\
4. & Kurangnya kegiatan \\
dalam wisata & \\
5. & Kurangnya nilai edukasi
\end{tabular} \\
\hline $\begin{array}{l}\text { Peluang (O) } \\
\text { 1. Adanya penyuluhan kepada } \\
\text { masyarakat. } \\
\text { 2. Adanya Perda No } 6 \text { Tahun } 2017 \\
\text { tentang retribusi tempat wisata. } \\
\text { 3. Telah terbentuknya Kelompok } \\
\text { Sadar Wisata ACl sebagai } \\
\text { pengelola. } \\
\text { 4. Keterlibatan masyarakat dalam } \\
\text { usaha wisata } \\
\text { 5. Adanya dukungan dari pemerintah }\end{array}$ & 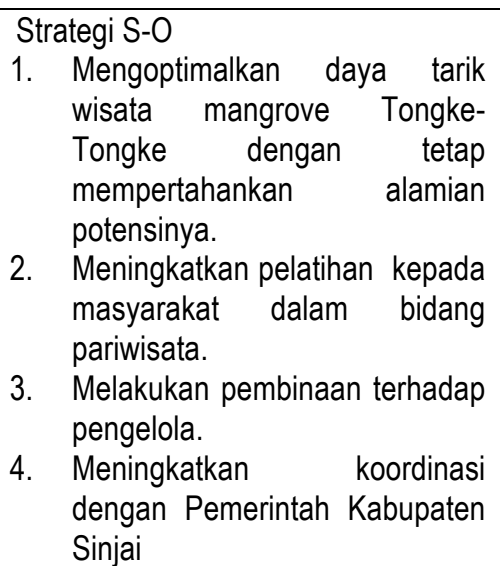 & 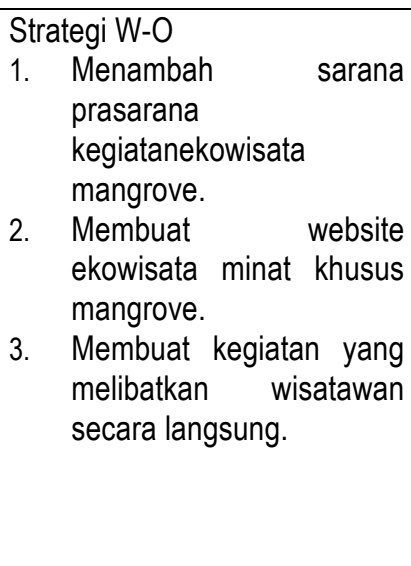 \\
\hline $\begin{array}{ll}\text { Ancaman }(\mathrm{T}) \\
\text { 1. } \\
\text { Kurangnya tenaga profesional } \\
\text { dalam bidang pariwisata } \\
\text { 2. Anggaran yang terbatas dalam } \\
\text { pengelolaan. } \\
\text { 3. Kurangnya sosialisasi dari } \\
\begin{array}{l}\text { pemerintah } \\
\text { 4. Kurangnya keterlibatan } \\
\text { masyarakat dalam perencanaan }\end{array}\end{array}$ & $\begin{array}{l}\text { Strategi S-T } \\
\text { 1. Melakukan kerjasama dengan } \\
\text { pihak lain yang berkompoten } \\
\text { dalam ekowisata. } \\
\text { 2. Mengajukan usulan anggaran } \\
\text { pengembangan ekowisata.. } \\
\text { 3. Meningkatkan sosialisasi dan } \\
\text { keterlibatan masyarakat dalam } \\
\text { perencanaan ekowisata. }\end{array}$ & 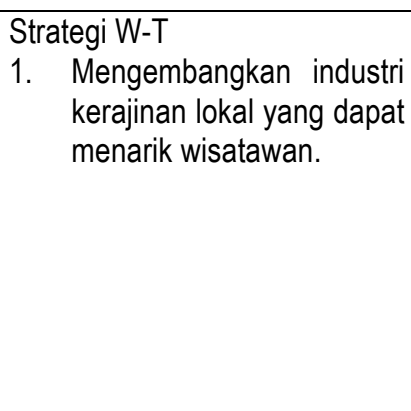 \\
\hline
\end{tabular}

Gambar 7. Matriks SWOT Pengembangan Ekowisata Mangrove Tongke-Tongke di Kabupaten Sinjai 
Kabupaten Sinjai menunjukkan bahwa strategi yang memiliki prioritas tinggi untuk dilaksanakan dalam pengembangan ekowisata mangrove Tongke-Tongke berada pada kuadran I. Kuadran I menggambarkan bahwa situasi yang sangat baik karena ada kekuatan yang dimanfaatkan untuk meeraih peluang yang menguntungkan, sehingga dapat digunakan strategi agresif atau strategi pertumbuhan. Hal ini berarti bahwa pada wisata mangrove Tongke-Tongke memiliki peluang dan kekuatan sehingga memiliki kesempatan untuk tumbuh dan berkembang.

\subsubsection{Strategi S-O}

\section{a. Mengoptimalkan daya tarik wisata mangrove Tongke-Tongke dengan tetap mempertahankan kealamian potensinya.}

Pengembangan wisata mangrove Tongke-Tongke sebagai kawasan ekowisata perlu mempertahankan kealamian potensi dan mengoptimalkan daya tarik wisata yang ada. Berdasarkan hasil penelitian, sebagian besar responden tertarik mengunjungi wisata mangrove Tongke-Tongke karena kealamian panorama hutan mangrovenya. Hal ini membuktikan bahwa pesona wisata mangrove Tongke-Tongke begitu besar bagi wisatawan bahkan sebelum pengembangan dilakukan dengan optimal, antusias kunjungan wisatawan cukup tinggi. Disisi lain perlu adanya penelitian tambahan dan lebih mendalam yang dilakukan terkait potensi flora dan fauna maupun potensi lainnya yang bisa digali untuk kegiatan ekowisata pada kawasan hutan mangrove Tongke-Tongke.

Hasil penelitian Karlina (2011), menyebutkan kegiatan ekowisata yang dapat dilakukan di kawasan mangrove Pantai Tanjung Bara, Kutai Timur meliputi pengamatan burung (bird watching), pengamatan satwa (animal watching), menikmati keindahan vegetasi mangrove dengan sarana jembatan kayu (board walk), memancing ikan (fishing), bersampan diantara vegetasi mangrove (canoeing) dan melakukan fotografi. Sedangkan Wahyuni dkk (2006), mengemukakan kegiatan ekowisata minat khusus mangrove yang dikembangkan di Ngurah Rai Bali berdasarkan potensi kawasan mangrove sebagai obyek daya tarik wisata sekaligus sebagai upaya rehabilitasi dan konservasi kawasan mangrove adalah program mangrove education tour and tracking, bird watching, fishing, mangrove tree plantation or adoption, canoeing and boating.

\section{b. Meningkatkan pelatihan terhadap masyarakat dalam bidang pariwisata.}

Pengembangan ekowisata pada wisata mangrove Tongke-Tongke perlu partisipasi dan keterlibatan masyarakat didalamnya. Pelatihan kepariwisataan perlu dilakukan oleh pemerintah Kabupaten Sinjai dalam hal ini Dinas Pariwisata Sinjai kepada masyarakat di Desa Tongke-Tongke yang kurang sumberdaya manusia dalam bidang ekowisata. Pelatihan ini dilakukan guna meningkatkan keterampilan dan kompetensi masyarakat di Desa Tongke-Tongke yang terlibatdi dalam melakukan usaha wisata yang dijalani. Jenis pelatihan yang dapat mendukung pengembangan ekowisata berbasis masyarakat antara lain keterampilan dalam etika pelayanan, bahasa Inggris dasar, interpretasi keanekaragaman flora dan fauna, inventarisasi objek dan daya tarik wisata, boga,pembuatan dan pemasaran souvenir, manajemen dan akuntansi sederhana.

Menurut Untari (2009), keterampilan yang dapat dilakukan kepada masyarakat dalam pengembangan ekowisata adalah pelatihan-pelatihan yang bersifat teknis dan manajerial karena dalam ekowisata berbasis masyarakat, masyarakat berperan sebagai pengelola sekaligus pelaksana kegiatan. Dalam penyelenggaraan pelatihan tersebut perlu adanya kerjasama dengan pihak-pihak yang memiliki kompetensi di bidangnya, misalnya untuk kegiatan interpretasi keanekaragaman flora dan fauna diperlukan kerjasama dengan perguruan tinggi bidang kehutanan serta perguruan tinggi bidang pariwisata.

\section{Melakukan pembinaan terhadap pengelola obyek wisata.}

Pengelola obyek wisata memiliki peranan yang penting dalam pengembangan mangrove Tongke-Tongke sebagai kawasan ekowisata nantinya. Perlu adanya suatu upaya pembinaan terhadap Kelompok Sadar Wisata $\mathrm{ACl}$ selaku pengelola kawasan wisata mangrove Tongke-Tongke untuk meningkatkan kompetensi dalam bidang pariwisata. Siagian dkk (2014), menyebutkan pengembangan ekowisata mangrove dilakukan dengan mengadakan pelatihan tambahan kepada kelompok masyarakat pengelola. Tujuan pelatihan tersebut agar masyarakat pengelola kawasan wisata bisa berbagi tentang pendidikan lingkungan kepada wisatawan. Jika kompetensi dan kemampuan dalam bidang pariwisata meningkat maka pengelolaannya pun akan menjadi lebih optimal. Pembinaan untuk pengelola tersebut dapat berupa studi banding yang dilakukan daerah-daerah pariwisata yang perkembangannya sangat signifikan seperti Bali dan Lombok. Dengan adanya studi banding ini 
pengelola obyek wisata mangrove Tongke-Tongke dapat mengenali potensi wisata yang ada di Desa TongkeTongke dan dapat dikembangkan secara lebih optimal.

d. Meningkatkan Koordinasi antara Pemerintah Kabupaten Sinjai dengan pengelola obyek wisata

Pengembangan hutan mangrove Tongke-Tongke sebagai kawasan ekowisata memerlukan peranan dan dukungan pemerintah daerah (Dinas Pariwisata Sinjai). Kerjasama dan koordinasi antara pihak pengelola kawasan dan pemerintah Kabupaten Sinjai dalam pengembangan ekowisata di kawasan mangrove TongkeTongke perlu dilakukan sebagai upaya mewujudkan pengembangan ekowisata mangrove dan konservasi kawasan mangrove berkelanjutan. Hal ini perlu dilakukan sebagai landasan utama untuk mendukung pengembangan ekowisata mangrove yang kondusif dan berkelanjutan berdasarkan kebijakan lingkungan, politik dan ekonomi yang berlaku.

Karlina (2011), menyatakan bentuk koordinasi yang dilakukan oleh pemerintah dan pengelola dalam pengembangan ekowisata mangrove di kawasan Pantai Tanjung Bara, Kutai Timur antara lain: (a) Persamaan persepsi tentang perlindungan dan pemanfaatan sumberdaya ekosistem mangrove sebagai obyek ekowisata (b) Keterpaduan tentang tata guna lahan terkait pengembangan ekowisata mangrove (c) Meningkatkan penelitian dan pengembangan keanekaragaman hayati yang ada pada kawasan mangrove (d) Monitoring dan evaluasi dampak kegiatan ekowisata mangrove.

\subsubsection{Strategi $W-0$}

a. Menambah sarana prasarana untuk kegiatan ekowisata mangrove.

Dalam mewujudkan pengembangan wisata hutan mangrove Tongke-Tongke sebagai kawasan ekowisata maka pemerintah daerah perlu membangun sarana prasarana yang masih kurang. Beberapa sarana dan prasarana wisata yang terdapat di kawasan wisata mangrove Tongke-Tongke masih kurang dan belum cukup memadai untuk kegiatan ekowisata sehingga perlu untuk ditambah. Sarana prasarana wisata yang perlu ditambah meliputi menara untuk pengamatan burung, gazebo, papan interpretasi, dan kios-kios kerajinan. Karlina (2011), menyebutkan pengembangan ekowisata mangrove dilakukan dengan menambah fasilitas dan sarana kegiatan wisata. Penambahan fasilitas dan sarana yang dibutuhkan dalam menunjang kegiatan ekowisata minat khusus mangrove tersebut antara lain membuat jembatan kayu (board walk), menara pengamatan (untuk kegiatan bird watching dan animal watching), shelter, pondok informasi, papan interpelasi, areal persemaian, dan perahu kayu.

b. Melakukan promosi ekowisata mangrove Tongke-Tongke

Hal penting yang perlu dilakukan dalam pengembangan wisata hutan mangrove Tongke-Tongke sebagai kawasan ekowisata adalah melakukan promosi wisata. Promosi ekowisata dilakukan dengan tujuan untuk meningkatkan kunjungan wisatawan serta memberikan insentif ekonomi yang bertujuan untuk konservasi lingkungan dan peningkatan kesejahteraan masyarakat Desa Tongke-Tongke. Umam dkk (2012), menyatakan bahwa promosi wisata dilakukan melalui media cetak maupun media elektronik untuk mendapatkan dukungan dan partisipasi masyarakat Wonorejo maupun masyarakat Surabaya dengan cara mempromosikan Ekowisata Mangrove Wonorejo Surabaya melalui penyebaran brosur, pamfle, pemasangan spanduk-spanduk, media internet (berupa website), televisi maupun radio, dan peta wisata di biro perjalanan dan fasilitas umum. Wisatawan yang telah berkunjung juga dapat menjadi sarana promosi yang efektif untuk menyampaikan kepada keluarga, kolega dan teman.

\section{c. Membuat kegiatan yang melibatkan wisatawan secara langsung}

Dalam rangka pengembangan ekowisata pada wisata hutan mangrove Tongke-Tongke kedepannya maka, perlu adanya kegiatan-kegiatan yang dapat melibatkan wisatawan secara langsung sehingga ada nilai edukasi maupun pengalaman baru yang didapat oleh wisatawan selama berkunjung. Pranatha dkk (2015), menyatakan bahwa keterlibatan langsung wisatawan selama berkunjung pada ekowisata mangrove Teluk Benoa, Bali dilakukan dengan aktifitas yakni memberi makan kepiting dan mencoba mengambil kepiting dari lubang dan sela-sela tanaman mangrove, kegiatan pengamatan burung, living class mangrove dan penanaman bibit mangrove, kegiatan outbound, bersampan, dan berwisata kuliner. Kegiatan ekowisata yang dapat dilakukan oleh wisatawan pada kawasan mangrove Tongke-Tongke diantaranya: (a) Berkeliling dengan perahu untuk menikmati panorama hutan mangrove (b) Mengamati satwa yang ada melalui menara pengamatan yang akan 
dibangun (c) Melibatkan wisatawan dalam menanam mangrove sebagai upaya untuk mendukung konservasi mangrove (d) Mengajak wisatawan melihat langsung proses pembuatan ikan asap yang menjadi kuliner khas Desa Tongke-Tongke.

\subsubsection{Strategi S-T}

a. Melakukan kerjasama dengan pihak yang berkompoten dalam ekowisata.

Untuk mengembangkan ekowisata pada wisata hutan mangrove Tongke-Tongke maka pemerintah daerah perlu melakukan kerjasama dengan para pihak atau ahli ekowisata. Kerjasama dapat dilakukan oleh pemerintah Kabupaten Sinjai dengan perguruan tinggi bidang pariwisata atau kehutanan untuk peningkatan kemampuan bahasa Inggris, tata boga dan etika pelayanan. Sedangkan untuk manajemen, akuntansi sederhana, pembuatan dan pemasaran souvenir dapat bekerjasama dengan praktisi bidang industri rumah tangga. Untuk meningkatkan sumberdaya manusia di bidang ekowisata maka pemerintah perlu melakukan kerjasama dengan pihak yang berkompeten guna pengembangan ekowisata mangrove Tongke-Tongke. Kerjasama tersebut dapat dilakukan dengan pakar dan ahli ekowisata dari Fakultas Kehutanan Universitas Hasanuddin Sulawesi Selatan.

b. Mengalokasikan anggaran pengembangan ekowisata mangrove Tongke-Tongke.

Pemerintah Kabupaten Sinjai perlu mengalokasikan anggaran untuk pengembangan pariwisata di Kabupaten Sinjai terutama untuk pengembangan wisata mangrove Tongke-Tongke sebagai kawasan ekowisata. Pengembangan sarana dan prasarana obyek wisata mangrove Tongke-Tongke selama ini masih terkendala dengan kurangnnya anggaran yang dimiliki. Diberlakukannya Perda Nomor 6 Tahun 2017 menjadi payung hukum bagi pemerintah untuk mengalokasikan anggaran pengembangan obyek wisata mangrove TongkeTongke yang nantinya akan menjadi salah satu sumber Pendapatan Asli Daerah (PAD) Kabupaten Sinjai dari sektor pariwisata. Dengan adanya ketersediaan anggaran yang cukup maka pengelolaan ekowisata mangrove Tongke-Tongke akan menjadi lebih optimal.

c. Meningkatkan sosialisai dan keterlibatan masyarakat dalam perencanaan ekowisata.

Keterlibatan masyarakat dalam mendukung pengembangan ekowisata pada wisata hutan mangrove Tongke-Tongke perlu dilakukan. Sosialisasi kepada masyarakat terkait kebijakan pemerintah menjadi sangat penting. Hal ini dimaksudkan agar pemerintah dan masyarakat menjadi sejalan dalam pengembangan ekowisata mangrove Tongke-Tongke ke depan. Sosialisasi ini hendaknya juga ditekankan kepada masyarakat untuk meningkatkan pemahaman masyarakat akan dampak negatif terhadap lingkungan akibat perusakan sumberdaya alam biofisik dan akibat pencemaran lingkungan. Hingga saat ini masih terdapat pembuangan sampah yang masih terjadi di beberapa titik pada kawasan hutan mangrove Tongke-Tongke.

Dalam mendukung pengembangan ekowisata mangrove Tongke-Tongke maka masyarakat perlu dilibatkan secara penuh dalam perencanaan, pelaksanaan, dan pengawasan untuk keuntungan masyarakat setempat. Selain itu pelibatan masyarakat sejak perencanaan, pelaksanaan, hingga pengawasan akan mempermudah pengembangan ekowisata mangrove Tongke-Tongke sebagai upaya untuk mendukung konservasi lingkungan dan juga meningkatkan pendapatan masyarakat. Prajana dkk (2015), menyebutkan keterlibatan masyarakat dalam perencanaan ekowisata mangrove berbasis masyarakat dilakukan dengan berpartisipasi dalam pengembangan, partisipasi dalam pembuatan keputusan, partisipasi dalam pelaksanaan dan perjalanan prosesnya, partisipasi dalam pembagian keuntungan ekonomi. Partisipasi masyarakat yang aktif dapat mendorong pengembangan ekowisata menjadi lebih optimal.

\subsubsection{Strategi $W-T$}

a. Mengembangkan industri kerajinan lokal yang dapat menarik wisatawan.

Pengembangan hutan mangrove Tongke-Tongke sebagai kawasan ekowisata dapat meningkatkan pendapatan masyarakat melalui kerajinan lokal berupa kuliner ikan asap, makanan olahan dari buah mangrove, dan souvenir dari kerang. Rata-rata wisatawan yang berkunjung ke wisata mangrove Tongke-Tongke merupakan pelajar dan mahasiswa. Wisatawan yang berkunjung tersebut rata-rata belum memiliki pekerjaan dan penghasilan tetap. Hal tersebut tentunya saja membuat wisatawan menjadi terbatas untuk membeli makanan, souvenir, dan kuliner yang dijual oleh masyarakat setempat. 
Hal ini dapat disiasati oleh masyarakat Desa Tongke-Tongke dengan menjual berbagai kuliner lokal diantaranya kuliner ikan asap dan makanan olahan dari buah mangrove dengan harga yang terjangkau oleh wisatawan yang belum memiliki pekerjaan dan penghasilan tetap tersebut. Dengan harga yang terjangkau akan menarik minat wisatawan untuk berbelanja dan juga mendatangkan manfaat ekonomi bagi masyarakat yang terlibat didalamnya. Atmoko (2010), menyebutkan masyarakat yang berdagang di sekitar kawasan ekowisata dengan menjual makanan seperti menu ikan air tawar, souvenir yang menjual berbagai pernak-pernik, kerajinan seperti akar kayu bakar bekas kebakaran hutan, rotan, daun pandan, daun nipah, dan bambu. Semua jenis makanan, souvenir, dan kerajinan tersebut dijual dengan harga yang cukup terjangkau sehingga bisa dinikmati oleh wisatawan yang datang berkunjung.

\section{KESIMPULAN}

Persepsi wisatawan secara umum mendukung dan menginginkan pengembangan wisata hutan mangrove Tongke-Tongke sebagai kawasan ekowisata. Dalam pengembangannya wisatawan juga memberikan saran antara lain dari: (a) Aspek aksesibilitas jalan perlu diperbaiki kondisi jalan yang rusak dan berlubang, (b) Aspek sarana prasarana perlu ditambah dan ditata sesuai kegiatan ekowisata, (c) Aspek obyek dan daya tarik wisata perlu dipertahankan panorama hutan mangrovenya, (d) Aspek pengelolaan perlu adanya pemandu wisata dan juga promosi wisata yang perlu ditingkatkan.

Faktor-faktor yang berpengaruh terhadap pengembangan mangrove Tongke-Tongke sebagai kawasan ekowisata meliputi: sarana prasarana, pengelolaan, keterlibatan masyarakat dalam usaha wisata, dan dukungan dari pemerintah Kabupaten Sinjai. Strategi pengembangan ekowisata mangrove Tongke-Tongke yang menjadi prioritas utama berada pada kuadran I (strategi S-O). Strategi yang dirumuskan pada kuadran I meliputi : (a) Mengoptimalkan daya tarik wisata mangrove Tongke-Tongke dengan tetap mempertahankan kealamian potensinya, (b) Meningkatkan pelatihan kepada masyarakat dalam bidang pariwisata, (c) Melakukan pembinaan terhadap pengelola, dan (d) Meningkatkan koordinasi dengan pemerintah Kabupaten Sinjai.

\section{DAFTAR PUSTAKA}

Blaikie, N. 2000. Designing Social Research The Logic of Anticipation. Malden, MA : Polity Press.

Bonewati, 2016. Peningkatan Kapasitas Dalam Pengembangan Pariwisata Berbasis Masyarakat Di Desa Olele Kabupaten Bone Bolango.Tesis Tidak di Terbitkan. Makassar: Program Pasca Sarjana PPW-UNHAS.

Harnaidah, 2016. Upaya Pemerintah Daerah Dalam Pengembangan Mangrove Forest Di Kecamatan Sinjai Timur. Skripsi Tidak di Terbitkan. Sinjai: Sekolah Tinggi Ilmu Sosial Dan Politik Muhammadiyah Sinjai.

Natsir, M. 2011. Analisis Empiris Efektivitas Mekanisme Transmisi Kebijakan Moneter Di Indonesia Melalui Jalur Suku Bunga (Interest Rate Channel) Periode 1990:2-2007:1. Kendari : Unhalu.

Rangkuti, F. 2009. Analisis SWOT: teknik membedah kasus bisnis (reorientasi konsep perencanaan strategis untuk menghadapi abad 21). PT.GramediaPustaka Utama. Jakarta.

Rusnaeni, 2013. Strategi Pengembangan Wisata Bahari Kabupaten Takalar. Tesis Tidak di Terbitkan. Makassar: Program Pasca Sarjana PPW-UNHAS.

Rutana, F, F. 2011. Studi Kesesuaian Ekosistem, Manggrove sebagai Objek Ekowisata di Pulau Kapota Taman Nasional Wakatobi Sulawesi Tenggara. Universitas Hasanuddin, Makasar.

Saparinto, C. 2007. Pendayagunaan Ekosistem Mangrove. Semarang : Effhar Offset.

Subadra, IN. 2008. Ekowisata sebagai Wahana Pelestarian Alam. Bali. [Online], http//Bali Tourism Watch Ekowisata sebagai Wahana Pelestarian Alam «Welcome to Bali Tourism Watch.htm [diakses tanggal 5 September 2017].

Suhandi, A.S. 2008. Community Based Tourism in Indonesia. Makalah KonvensiWisata Hasil Kerjasama ECEAT (European Centre for Ecotourism and Agricultural Tourism) dengan INDECON di Nusa Dua Bali 13-16 Maret2008 "Menciptakan Mata Rantai Penyedia (Supply) Pariwisata Berbasis Masyarakat di Kawasan Asia Selatan dan Asia Timur". 
Untari, R. 2009. Strategi Pengembangan Ekowisata Berbasis Masyarakat Di Zona Wisata Bogor BaratKabupaten Bogor. Sekolah Pascasarjana Institut Pertanian Bogor.Bogor.

Wahyuni, P.I., Ardhana, I., Sunarta, I.N. 2006. Evaluasi Pengembangan ekowisata di kawasan Tahura Ngurah Rai. Jurnal Ecotrophic 4 (1) : 49-56.

Yoeti, A. O. K. 2008. Perencanaan Strategi Pemasaran Daerah Tujuan Wisata. Jakarta. PT. Pradnya Paramita 